\title{
An Analysis of Causes of Sub-health State among College Teachers and Corresponding Countermeasures
}

\author{
Li HOU \\ Renmin University of China, Beijing, China \\ 13811860579@126.com
}

\begin{abstract}
Through a survey of the Sub-health State of 350 mid-aged and young college teachers in capital, we found that the Sub-health State among this group is very common and has affected their physical and mental well-being as well as their work. Therefore there is urgent need for them to take advantage of sports facilities in colleges to change the situation.
\end{abstract}

KEYWORD: College teacher; Sub-health State; Analysis and Countermeasures

The World Health Organization believes that Health is not just about being without sickness; it is a state of perfect physical and mental being. According to this definition, statistics show that the sum of people that is truly healthy (first state) or is bearing sickness (second state) is less than $2 / 3$ of the population. There are more than $1 / 3$ of people who are between the transitional stages of health and sickness. The World Health Organization refers to this as the "third state" while the public usually refers to this as being a "sub healthy state" or grey state. This indicates the intermediate state between perfect health and illness. Anybody is able to be classified in this category. If people in the third state deals with the condition appropriately, they will be able to make a gradual transition to perfect health. On the contrary, if handled inappropriately, they could acquire illnesses.

Young college teachers are considered to be a special group. Their health status is often ignored by others and themselves. It is often believed that the period in which the person's health is at its best is during their youth. This is especially the case when they have been through higher education. It would only make sense to categorize them as being in a state of perfect health. However, the survey results indicate otherwise.

This paper intends to discuss the factors preventing young college teachers from achieving perfect health, and suggest possible countermeasures to this problem by analyzing the results obtained from a self-made survey.

\section{INTRODUCTION}

Results were obtained by surveying 350 college teachers aged between 25 to 40 years old from 7 Universities in Beijing. North China University of Technology, Beijing Language and Culture University, Beijing Jiaotong University, Beijing Normal University, Capital University of Economics and Business, University of Science and Technology Beijing and Beijing University of Chemical Technology. The actual amount of surveys recovered was 321 , a recovery rate of $91.71 \%$. Of the 321 survey's received, 253 were male and 68 were women. $83 \%$ of the people surveyed had obtained a masters degree or above.

Results indicated that $38.12 \%$ of teachers have more than 12 kinds of the 70 sub-health symptoms listed. Only $20.6 \%$ of teachers evaluated themselves to be healthy. $33.25 \%$ of teachers are suffering from nervous breakdowns, mental disorders, chronic gastritis or other diseases. $50.19 \%$ of teachers believe themselves to be under the sub-healthy state, therefore causing an impact on their social function. Additionally, $68.22 \%$ of teachers are concerned about being in the sub-healthy state while $12.54 \%$ are very anxious about being categorized as being sub-healthy. $20.87 \%$ of people surveyed have suspicions that they are suffering from a disease.

These cases suggest that being in the sub-healthy state has seriously affected the physical and mental health of teachers. This in turn causes a certain negative impact on teaching and scientific research. Society should be more concerned with the health of young college teacher and be more aware of the transition away from the sub-healthy state. 


\section{ANALYSIS OF RELATED FACTORS}

Various Factors causing young college teachers to be in a sub-healthy state (see Table 1)

Table 1: Statistics for Factors Causing Young College Teachers to be in a Sub-Healthy State

\begin{tabular}{|l|l|l|l|}
\hline $\begin{array}{l}\text { Sort } \\
\text { Sequence }\end{array}$ & Influencing Factors & Amount & $\begin{array}{l}\text { Percentage } \\
(\%)\end{array}$ \\
\hline 1 & $\begin{array}{l}\text { Work Environment and } \\
\text { Psychological Factors } \\
\text { (Mental Stress, Heavy } \\
\text { Workload) }\end{array}$ & 712 & 75.42 \\
\hline 2 & $\begin{array}{l}\text { Work Achievement } \\
\text { (Teaching, Scientific Research } \\
\text { Achievement is not Ideal) }\end{array}$ & 698 & 73.94 \\
\hline 3 & $\begin{array}{l}\text { Lifestyle Factors } \\
\text { (Smoking, Drinking, Irregular } \\
\text { Lifestyle, Lack of Exercise) }\end{array}$ & 649 & 68.75 \\
\hline 4 & $\begin{array}{l}\text { Social Factors } \\
\text { (Social Change) }\end{array}$ & 474 & 50.21 \\
\hline 5 & $\begin{array}{l}\text { School Treatment Factors } \\
\text { (Wages, Housing) }\end{array}$ & 361 & 38.25 \\
\hline 6 & $\begin{array}{l}\text { Natural Factors } \\
\text { (Season and Weather Change) }\end{array}$ & 307 & 32.52 \\
\hline 7 & $\begin{array}{l}\text { Family Factors } \\
\text { (Economic Burden, Family } \\
\text { Disharmony) }\end{array}$ & 285 & 29.17 \\
\hline 8 & $\begin{array}{l}\text { Education and Professional } \\
\text { Pressure Factors }\end{array}$ & 1286 & 78.23 \\
\hline
\end{tabular}

\subsection{Work Environment and Psychological Factors}

Teaching is an occupation that has its own special characteristics. The diversity of teaching targets requires teachers to have multidimensional psychological orientation. Teaching demonstrations require teachers to strengthen their self image. The wide range of teaching content demands teachers to have a broad and profound knowledge of the subjects whilst constantly improving their cognitive structure. Additionally, due to the complexity of the job, teachers are required to have a strong ability to adapt to different situations and solid mental regulation. Due to the difficulty and high requirements needed in order to become a qualified teacher, the psychological burden and stress of teachers are increased. Secondly, the subject statuses of teachers in some Colleges are not very noticeable. Respect for teachers and respect for talent is not apparent. Additionally, huge increases of student enrolment have greatly enlarged the workload of teachers. Furthermore, due to the popularity of computer networks in colleges, the popularization of knowledge information has greatly improved. Teachers are no longer the only information source for students. This has led to a certain decline in the authority of teachers, causing an increase in pressure for some teachers.

\subsection{The Influence of Work Performance}

Colleges and Universities have generally adopted the evaluation system for evaluating the effects of a teacher's teachings. Many teachers teaching specialized subjects did not receive teacher training. Although they have had pre-employment training, there will more or less be problems with language expression and communication with students. To some extent, the academic level of some teachers is not very high. This has directly affected the students' assessment of teachers, causing a negative impact on the relationship between the teacher and the students. Subsequently resulting in an increase of psychological pressure for the teacher.

There are different types of work that teachers perform. Some hold a teaching position, some only deal with scientific research, some teach foundation courses (math, English etc.) whilst some teach professional courses. This has inevitably led to differences in academic competence. This particular situation is portrayed through the amount of published papers that has embodied this concept to their work. These papers are rigid indications of this evaluation.

\subsection{Factors of Interpersonal Relationship}

Good interpersonal relationships will undoubtedly lead to a good work attitude. Teachers have to deal with students, handle relationships between colleagues, family and other social relations. The social experience of young teachers is still shallow, especially those who have just graduated, thus it is inevitable that they will be stressed due to having trouble coordinating complicated interpersonal relationships. $45 \%$ of teachers who completed this survey felt that they were overstressed. $60 \%$ of those surveyed were unsatisfied with their work or life whilst 35\% did not have a friend they could confide in. This has caused them long-term psychological tension, resulting in adverse effects on their health.

\subsection{Influences of Lifestyle Factors}

Results show that a majority of teachers smoke, drink or have other bad habits. Additionally, most of them have irregular lifestyles, lack proper exercise or have dietary irregularities. This is one of the main factors for young college teachers to be in the subhealth category.

\subsection{Influence of Social Factors}

The country's major political and economic development has caused gradual changes to organizations, means of employment, costs and benefits, the ideology and value orientation of teachers have a diversified trend. Can economic benefits or status be an indication to ones success in 
a highly competitive commercial society? Do we choose to advance towards a materialistic life or do we continue with our low paying job, teaching.

\subsection{Influences of School Treatment Factors}

The current treatment of young college teachers is not considered to be very good. This is mainly because they do not have significant qualifications, wages are relatively low and most of them do not possess a lot of duties or funds. Results from the survey showed that $96.75 \%$ were dissatisfied with their wages. The halting of national welfare housing distribution and stubbornly high housing prices has caused a heavy economic burden to teachers. A lot of young teachers will continue to be in debt for most of their life.

\subsection{Influences of Natural Factors}

People may have trouble adapting to the changing of seasons. For example, in early spring, many teachers often feel tired. A change in weather can also lead to people being in a sub-healthy state. For instance, continuous rain for several days can cause one to feel depressed.

\subsection{Influences of Family}

Results from the survey show that $29.17 \%$ of teachers believe that family is one of the main reasons for their sub-health status. A heavy family burden, infants, underachieving children and sick parents are all factors than can have adverse effects to their health. Additionally, the occupation, cultural degree and economic status of life partners and parents are factors that were considered. Harmonious and happy families provide emotional support to teachers.

\subsection{Influences of Education Background and Professional Pressure}

Results show that a majority of those in the subhealth status are those whose highest educational background is a Bachelors degree. The second most amount of teachers with a sub-health status are those who have obtained a Masters degree. Teachers who have obtained a $\mathrm{PhD}$ have the least amount of people in the sub-health status. This trend may be related to the gradual increase of the academic requirements for teaching and research staff. Ones educational background could affect the opportunity of obtaining a promotion. The higher the educational background, the better treatment and personal accomplishment one would experience. In other words, the personal qualifications, high employment position, stability of status and good economic and living conditions will have a psychological impact on their personal sense of achievement. This in turn has certain simulative effects to ones health.

\section{PHYSICAL CONDITIONING COUNTERMEASURES}

Constant exercise is a vital factor for improving ones physical and mental health. Dr. Pastor, Sport Psychologist of Harvard University believes that exercise not only strengthens the body and mind, it also helps improve our personality. Exercise has its unique content and form of activity. It brings participants the happiness of learning, the joy of growth, the excitement of success, the relief of improvement and the thrill of winning. It improves collective strength, own value, self-improvement, competitiveness and observation skills. These satisfactions can eliminate nervousness, train a person's character, exercise ones will, promote ones intelligence, self-awareness and self-control. It also stimulates people's initiative, motivating people to pursue healthy and positive life goals.

Of the different methods for conditioning treatment for sub-healthy teachers, $65.21 \%$ of teachers chose self-treatment. $46.38 \%$ believed drug treatment was appropriate. Others chose to regulate their diet, change bad habits, psychological counseling, improving living and working environments and reduce stress as their preferred treatment methods. Less than a third $(32.42 \%)$ of teachers chose exercise. Of the teachers that did regular exercise, only $22.14 \%$ were in the subhealthy category.

\subsection{Improving the Ideological Understanding of Implementing "Lifelong Sports"}

Schools often have the concept of "health comes first". This is to instill the ideology of "lifelong sports". However, once we leave school and enter into society, we will distance away from exercise. We will only think to exercise when we have problems with our health. This situation is caused by a variety of elements. These include location factors, time factors, the nature of our work and family factors. However, the main element are personal factors as we have not developed a habit of exercising.

\subsection{Various Departments of Schools can Hold Sporting Events to Promote Exercise}

Only $22.23 \%$ of those surveyed participate in regular exercise. A majority of this percentage has just entered into a job (30 years old or less). In order to increase the enthusiasm of young teachers to participate in sports, schools must pay attention to this. Secondly, the various departments of the school 
have to cooperate with and support each other. Holdingregulor staff held competitions, making it compulsory for the attendance of teachers and providing guidance to teachers can gradually cause teachers to actively participate. Secondly, there should be more activities where the families of the teachers can also attend. This will cause a harmonious atmosphere and make everyone feel more relaxed and cheerful. In fact, these types of events already exist. However, the content is very monotonous and the number of activities and participants are becoming less and less. Now, we must effectively utilize various departments of the school in order to better the staff health and service.

\subsection{Aerobic Exercise Focused on Increasing Fitness}

In recent years, more and more aerobic exercises has been confirmed by scientific research to reduce anxiety, depression and improve the overall mood of the participant. Positive effects have been most prominent in cardio workouts. Therefore, the type of exercise and intensity of the workout should be based on every individual's situation. They should start from low intensity exercises.

\subsection{Make Full Use of the Sports Environment}

Colleges have rich sports resources. The hardware, sports venues and facilities continue to improve as colleges increase in size. This is especially the case lately where a lot of colleges are expanding. In addition, there are many skilled sports teachers and active students. Due to this, colleges are very suitable sporting venues. Teachers should make full use of these facilities and increase their fitness.

\subsection{Reduce Venue Fees and Vigorously Promote National Fitness}

Many College sports venues and social stadiums are open to the public for a fee. Every school has a different way of offering benefits to its teachers for using the venues. The most popular method is for the union to give every teacher an activity card.

\section{CONCLUSION}

The health problems of young teachers in colleges are increasingly becoming a point of concern. Improving their physical and mental health is not only related to their teaching and research, it is also related to the development of students and the future of higher education. Awareness should be brought to teachers in the sub-health category. Early prevention and intervention can prevent the worsening of their health. The treatment for those with sub-health status should be comprehensive. Psychological counseling and appropriate medication is an important factor for bringing them back to full health. Exercise is vital in the prevention and intervention of illness. Teachers should make full use of the sporting facilities in colleges in order to improve their health. This is so they can perform better in higher education teaching.

\section{REFERENCES}

[1] Wang Hongfu. Analysis of Young University Teachers' "sub healthy state". Sports Teachers, 2005 (volume 3).

[2] He Gang; Jiang Xin; Wang Rong. The Health of Young Teachers in a University in Beijing. Analysis of Chinese School Health, 2009 (volume 2).

[3] Pan Li; Ye Shaocan. Effects of Psychological Problems of Young Teachers in Colleges and Universities and Adjustment Strategy. Journal of HeFei University of Technology (SOCIAL SCIENCE EDITION), 2007 (volume 3).

[4] Jiang Junna; Liu Jianjun; Tan Yili. Survey and Analyis of Health Status of Young Teachers in Colleges and Universities of Hebei Province. Chinese Staff Education, 2013 (volume 16). 